\title{
Erratum to: A supplier offer modification approach based on fuzzy systems for automated negotiation in e-commerce
}

Bahador Shojaiemehr $^{1}$ • Marjan Kuchaki Rafsanjani ${ }^{2}$

Published online: 25 August 2016

(C) Springer Science+Business Media New York 2016

Erratum to: Inf Syst Front

DOI $10.1007 / \mathbf{s} 10796-016-9688-0$

The biography of Marjan Kuchaki Rafsanjani was incorrect.

The original version has been corrected.

The online version of the original article can be found at http://dx.doi. org/10.1007/s10796-016-9688-0

\footnotetext{
Marjan Kuchaki Rafsanjani

kuchaki@uk.ac.ir

Bahador Shojaiemehr

bahadormehr@gmail.com

1 Young Researchers and Elites Club, Science and Research Branch, Islamic Azad University, Tehran, Iran

2 Department of Computer Science, Faculty of Mathematics and Computer, Shahid Bahonar University of Kerman, Kerman, Iran
} 